\title{
Interactive comment on "Uncertainties in breakup markers along the Iberia-Newfoundland margins illustrated by new seismic data" by Annabel Causer et al.
}

\section{Anonymous Referee \#3}

\section{Received and published: 5 December 2019}

General comments: The aim of the manuscript submitted by Causer et al. is to discuss breakup markers along the Iberia-Newfoundland margins based on new seismic data. The theme of the manuscript is of major scientific interest, since neither the nature, not the timing and location of breakup are well constrained along the lberia-Newfoundland margins. Many papers, some of which are very recent, have been dedicated to this problem. I have to admit that I did not find new ideas, or new, well constrained observations that add something new to the subject. Indeed, the interpretation of the new seismic data lack a rigorous interpretation and observations and interpretations are mixed and difficult to follow (for some further comments see comments below). The manuscript reads more like a report referring to old studies and only very few new ob- 
servations are added. Most disturbing is that some of the latest studies, that come to almost the same conclusions, are only marginally referred or partly not discussed. This omission weighs heavily and discredit the authors. Apart from these points, there are several other points (see comments below) that makes that this manuscript can not be accepted in its present version.

Interactive

Specific comments: I.30: here and elsewhere in the paper the authors make statements that are similar to the papers of Nirrengarten et al, without citing their work. Actually, most of the conclusions reached in this paper are similar to those by Nirrengarten et al. 2017 and 2018, thus, referring to these results is necessary. I would propose that the authors should discuss how their results are different from those of Nirrengarten et al. 2017 and 2018. I do not really see a big difference. Moreover, the papers of Stanton et al. 2015 and Nirrengarten et al. 2018 that deal with the same subject are not referred to. I. 25: the SDR packages need to be better described; what is the origin (magmatic) and the significance of the SDR package? I can not find them in the figures I.130 to 150: the tectonic setting part is completely outdated. A lot of work has been done in the last years that need to be referred to. I.218 Dataset and methods section need to be rewritten and more details about the data presented in the paper need to be presented. 1.265 to 345 The description of the seismic lines mixes observations with interpretations. Many questions remain open, such as how syn-rift 1 and 2 have been defined, where are possible limits, how were different types of basement defined and what are the evidence for magmatic additions (there are many more questions that arise by looking the seismic interpretations). The presentation of the data needs to include the presentation of the seismic section (without interpretation), a line drawing and the presentation. As presented here, I cannot follow the interpretations and many of the assumption are not back up by observations. The presentation of the seismic data is insufficient and does not corresponds to the standard of scientific papers. I.360 to 400: this section does not really discuss new ideas and does not built on the observations neither. Most of what is said here is old and outdated (the authors seem to have missed the research on the lberia-Newfoundland margins of the last 5

Printer-friendly version

Discussion paper

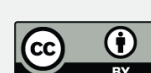


years??) I.405 to 460: This section reads more as a report than a discussion chapter.

Interactive comment on Solid Earth Discuss., https://doi.org/10.5194/se-2019-141, 2019.

Interactive

comment 